\title{
Medication-related adverse events in health care-what have we learned? A narrative overview of the current knowledge
}

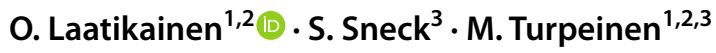

Received: 13 July 2021 / Accepted: 28 August 2021 / Published online: 6 October 2021

(c) The Author(s) 2021

\begin{abstract}
Purpose Although medication-related adverse events (MRAEs) in health care are vastly studied, high heterogeneity in study results complicates the interpretations of the current situation. The main objective of this study was to form an up-to-date overview of the current knowledge of the prevalence, risk factors, and surveillance of MRAEs in health care.

Methods Electronic databases (PubMed, MEDLINE, Web of Science, and Scopus) were searched with applicable search terms to collect information on medication-related adverse events. In order to obtain an up-to-date view of MRAEs, only studies published after 2000 were accepted.

Results The prevalence rates of different MRAEs vary greatly between individual studies and meta-analyses. Study setting, patient population, and detection methods play an important role in determining detection rates, which should be regarded while interpreting the results. Medication-related adverse events are more common in elderly patients and patients with lowered liver or kidney function, polypharmacy, and a large number of additional comorbidities. However, the risk of MRAEs is also significantly increased by the use of high-risk medicines but also in certain care situations. Preventing MRAEs is important as it will decrease patient mortality and morbidity but also reduce costs and functional challenges related to them. Conclusions Medication-related adverse events are highly common and have both immediate and long-term effects to patients and healthcare systems worldwide. Conclusive solutions for prevention of all medication-related harm are impossible to create. In the future, however, the development of efficient real-time detection methods can provide significant improvements for event prevention and forecasting.
\end{abstract}

Keywords Medication-related adverse events $\cdot$ Health care $\cdot$ Patient safety $\cdot$ Patient harm $\cdot$ Adverse drug events · Medication errors

\section{Introduction}

During the twentieth century, several cases of severe medicationrelated adverse events (MRAEs) gained attention worldwide resulting in general understanding of the risk of patient harm presented every time medicines are administered. As a result, the structures of pharmacological care were revolutionized in all stages, from research and development to continuous surveillance

O. Laatikainen

Outi.laatikainen@oulu.fi

1 Research Unit of Biomedicine and Medical Research Center Oulu, Oulu, Finland

2 Department of Pharmacology and Toxicology, University of Oulu, Oulu, Finland

3 Oulu University Hospital, Oulu, Finland and risk-analyses stretching the entire lifecycle of each medicine. Since then, medical care has been characterized by careful assessment of risk and benefit in order to ensure safe and effective medical care.

It is apparent that MRAEs cause different levels of patient harm, with the most serious events resulting in an increase in morbidity and mortality worldwide [1-3]. The effects of the less serious cases are often poorly detected but are, however, known to decrease medication compliance and result in suboptimal medical care among patients making the execution of cost-effective, rational medication difficult. Aside from this, MRAEs are connected to a variety economic and functional challenges that strain the healthcare systems [4].

Accordingly, research focusing on MRAEs has been ongoing actively in order to describe the issue and present potential solutions for improved prevention. Understanding the risk factors and mechanisms of MRAEs is also important 
in both developing medication processes within healthcare organizations but also safer care practices nationally and internationally. Although previous research in this field has been thorough and frequent, the general interpretations have been complicated by the high heterogeneity in event terminology, study settings, and methods used. Consequently, forming a clear overview of the issue can be hampered by comparing the vastly differing results of different studies, creating an obvious need for coherent and concise summary of the topic. The main objective of this narrative review was to collect recent information from studies conducted on the topic of MRAEs in health care, in order to describe the overall prevalence, risk factors, and surveillance methods currently used.

\section{Methods}

Electronic databases (PubMed, MEDLINE, Web of Science, and Scopus) were thoroughly searched with applicable search terms to detect relevant research on prevalence, risk factors, economic effects, and surveillance methods of medication-related adverse events. The search method and search terms are presented in Fig. 1. To form as up to date overview of the current situation as possible, only studies published after 2000 were included in this review. Systematic reviews and meta-analyses were preferred over other research, but high-quality papers describing original research were accepted as well. All articles that were not published in English were excluded. As this review was not conducted as a systematic review, information drawn from different articles was not filtered according to heterogeneity in terminology concerning MRAEs. This approach was selected as it also highlights the challenges associated with research concerning MRAEs. However, the differences in research terminology were acknowledged by reporting each drawn data as they were reported in the original article to avoid bias caused by mixed definitions.

\section{Definitions}

In this study, ADE is defined according to the Institute of Medicine (IOM) as an injury resulting from medical intervention related to a drug and ADR according to the World Health Organization (WHO) as noxious or unintended response to a drug occurring at doses normally used in man [5, 6]. ME is defined by Ferner and Aronson as "a failure in the treatment process that leads to, or has the potential to lead to, patient harm," and that can appear in any part of the medication process, e.g., in logistics, prescribing, handling, administering, or dispensing [7]. If not intercepted, MEs can lead to ADEs and ADRs. The term MRAE is used to describe all undesired events in pharmacotherapy, i.e., ADE, $\mathrm{ADR}$, and MEs. The interplay of the terms is presented in Fig. 2.

\section{Prevalence of MRAEs}

The number of studies focusing on all types of MRAEs has increased significantly over the past 30 years. Research has provided valuable insight into the frequency and nature of MRAEs but has also brought awareness of the heterogeneity between prevalence rates of individual studies (Table 1). Accordingly, depending on a variety of study characteristics, the prevalence of MEs varies anywhere from 0.8 errors per patient days to $22.2 \%$ of all administered medicines, and the prevalence of ADEs and ADRs from 12.9 ADEs per 1000 patient days to $58 \%$ of patients and 3.5 ADRs per 1000 emergency department (ED) visits to $14.7 \%$ of patients, respectively [8-13]. Similarly, high heterogeneity is seen in the results of various systematic reviews and meta-analyses conducted on this topic: in a meta-analysis by de Vries et al., the frequency of hospital-acquired ADEs was found $9.2 \%$ of all patients, but the numbers between meta-analyses differ up to 19\% [14]. For in-hospital ADRs, the results of individual meta-analyses vary between 1.6 to $16.8 \%$ [15-17]. In a review by Keers et al., the overall prevalence for in-hospital MEs was found 19.6\% [18]. Furthermore, as individual studies focusing on outpatient ADEs and ADRs causing unplanned hospitalizations to range between 2 and 5\% in the overall population, a metaanalysis by Alhawassi et al. targeting unplanned hospitalizations of geriatric patients shows variation from 5 to $46 \%$, with a mean prevalence of $11 \%$ [1,4, 19-21]. Moreover, in a recent review, it was discovered that all MRAEs increase the risk of hospital readmission by a median of $21 \%$, thus increasing the overall impact of in-hospital events [22].

The main underlying reasons to the high heterogeneity in MRAE prevalence are largely due to differences in used definitions and study populations. Studies defining ADE and ADR in a way that includes events and reactions caused by misuse of drugs, e.g., abusing narcotics or using drugs to cause self-harm, and include more events than those excluding these types of situations through event definition. Differences may also arise from the interchangeable use of terms $\mathrm{ADE}$ and ADR, as well as incoherent association of MEs, ADEs, and ADRs [30]. In a mixed sample, detected numbers of MRAEs can differ substantially compared to studies focusing on specific risk groups $[1,31]$. For example, ICU patients are known to be more susceptible to MRAEs with prevalence rates varying from 3.3 to $72.5 \%$ of patients whereas ME rates for psychiatric patients range from 10.6 to $17.5 \%$ [3, 32-34]. These interdisciplinary differences can largely be associated with both the frequency of medication 
Fig. 1 The database search method used in the narrative review

\section{Search terms}

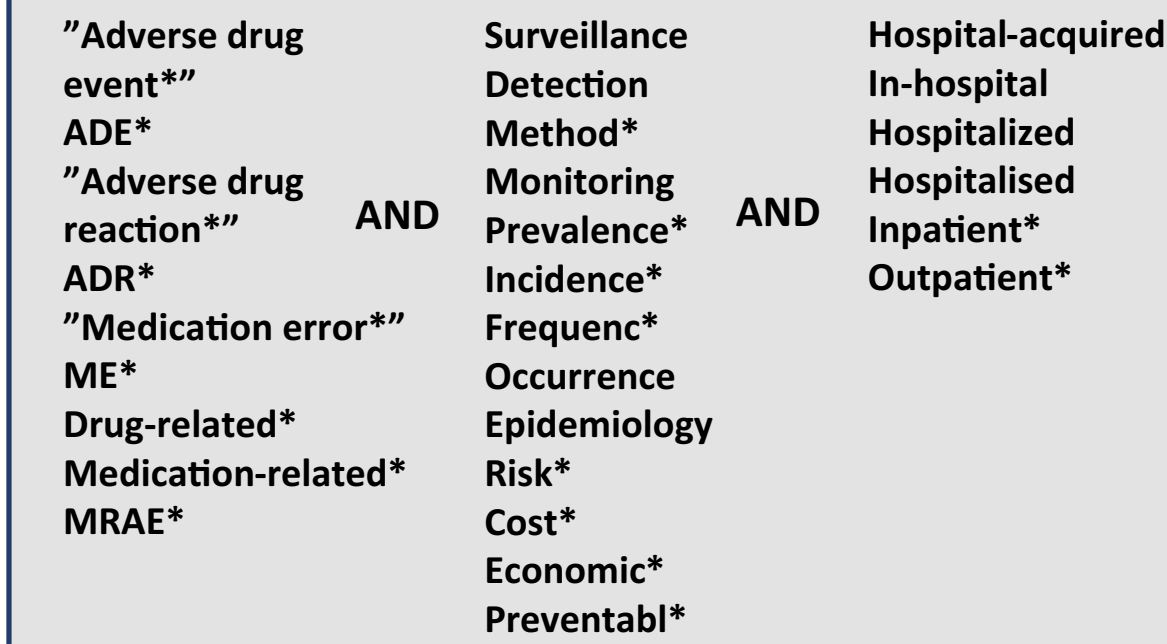

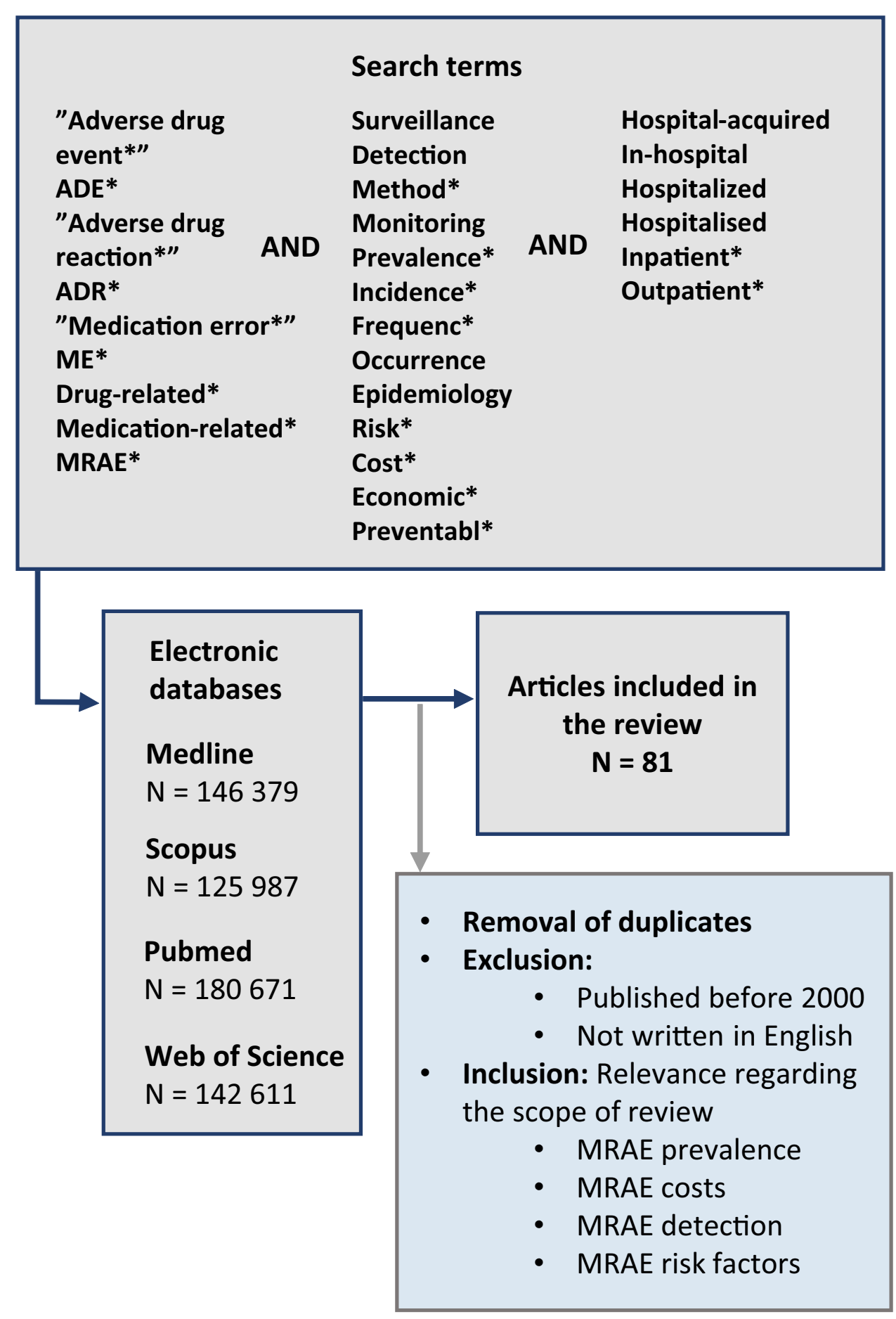

use and the profile of commonly used medicines within organizations [33, 34].

\section{Economic consequences}

MRAEs also have an important implication in healthcare economics and organizational functions [4, 8]. In this review, economic effects are presented as euros (exchange rate $1 €=1.17$ \$US). Depending on the country or area, the total annual costs of all MRAEs can vary significantly. In the European union, the annual costs are estimated to reach $€ 79$ billion, whereas, in the USA, the estimates vary from $€ 89.62$ billion ( $\$ 76.6$ billion) to $€ 207.56$ billion ( $\$ 177.4$ billion) [35-38]. When different event types are singled out, estimates of in-hospital ME costs vary between $€ 2.58$ (unnecessary immunization in children) to $€ 111727$ (litigation costs), 
Fig. 2 The interplay of different medication-related adverse events

\section{Medication-related adverse events}

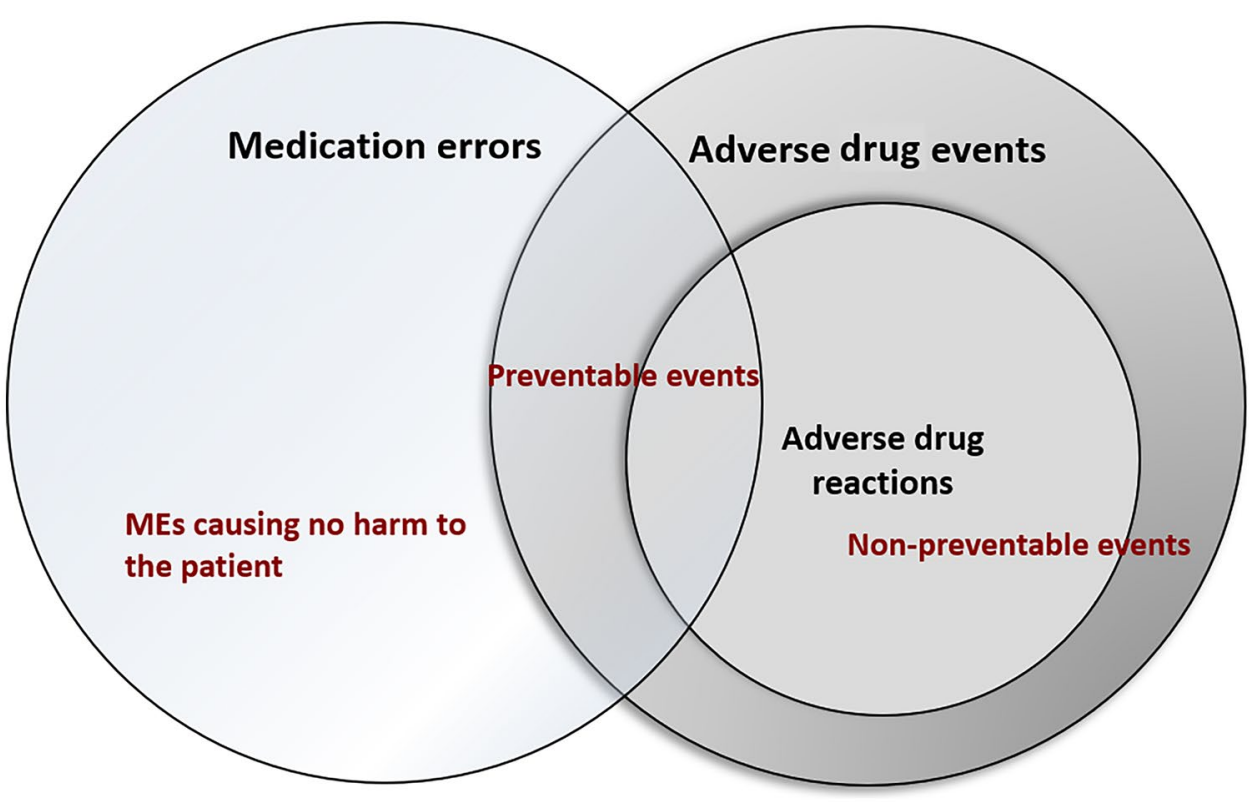

and for in-hospital ADEs and ADRs, the costs range between $€ 2647$ and $€ 7192$ [4, 39-41]. When an ADE or ADR occurs in an outpatient setting and causes hospitalization, it is estimated to cause $€ 6670$ (\$5700) excess costs [42].

Much of the variation between cost estimates is determined by the seriousness of the event, where minor events tend to cause smaller expenses and life-threatening events that require additional treatment and surveillance rapidly increasing the expenses [4]. Furthermore, care setting also plays important role in cost formation, and lower eventspecific costs have been connected to primary care and non-intensive care compared to events in tertiary care and intensive care units [43]. Interestingly, it has been found that preventable events cause up to 1.8 -fold higher costs than non-preventable ones [37]. Additionally, higher costs have been linked to certain specific symptoms, such as fever, bleeding, diarrhea, and cardiac arrhythmias [40]. Typically, the underlying reasons creating excess costs in MRAEs are increased length of stay, medication costs (e.g., additional treatments, exams, or medicines), and mortality [4, 12, 44]. From societal viewpoint, indirect costs are also created by indirect consequences, such as sick leaves and outpatient care making the total economic impact much greater than often first assessed [45].

\section{Known risk factors for MRAEs}

The effect of different variables on the medication outcome is presented in Fig. 3.

\section{Population-based risk factors}

\section{Genetic factors and age}

Pharmacogenomics has shown that interindividual differences in the human genome can have a substantial effect to the ADME (absorption, distribution, metabolism, excretion) properties of medicines, causing inherent differences between individual patients in both therapeutic effects and the probability of ADEs [46-48]. However, several patientbased risk factors have also been detected, that are more generalizable to different patient groups at population level. Of these factors, studies have shown that higher age among patient has one of the strongest and most consistent evidence of increasing the susceptibility for MRAEs [1, 2, 39, 49-51]. Estimates show that MRAEs are up to 4 times more common in the elderly than in general population, in both inpatient and outpatient settings [1, 52]. As with current understanding, this results from multiple interconnected causes that occur with aging, including alternation in both pharmacodynamics (e.g., altered receptor function) and pharmacokinetics (lowered renal function, lowered metabolic capacity, changes in body mass distribution), increased complexity of comorbidities, and polypharmacy [1, 53, 54]. As all these factors would also independently increase the risk for MRAEs, it is obvious that the accumulation of them with aging is bound to cause problems, especially when combined with frailty and lowered capacity to sustain body homeostasis in the elderly. As a result, predicting the effects of even commonly used medicines can prove challenging in the elderly. 


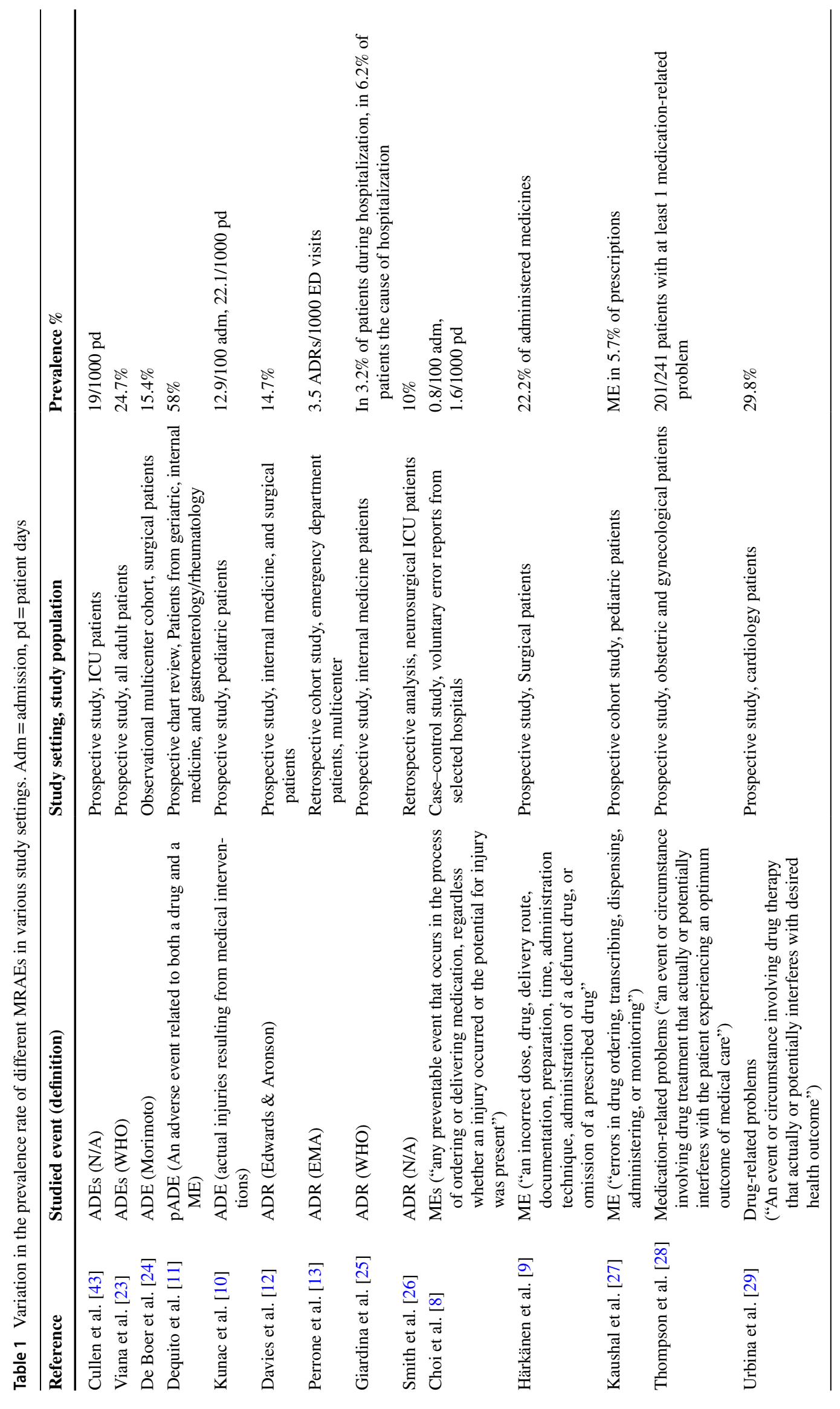


Fig. 3 Variables affecting the different outcomes of pharmaceutical care

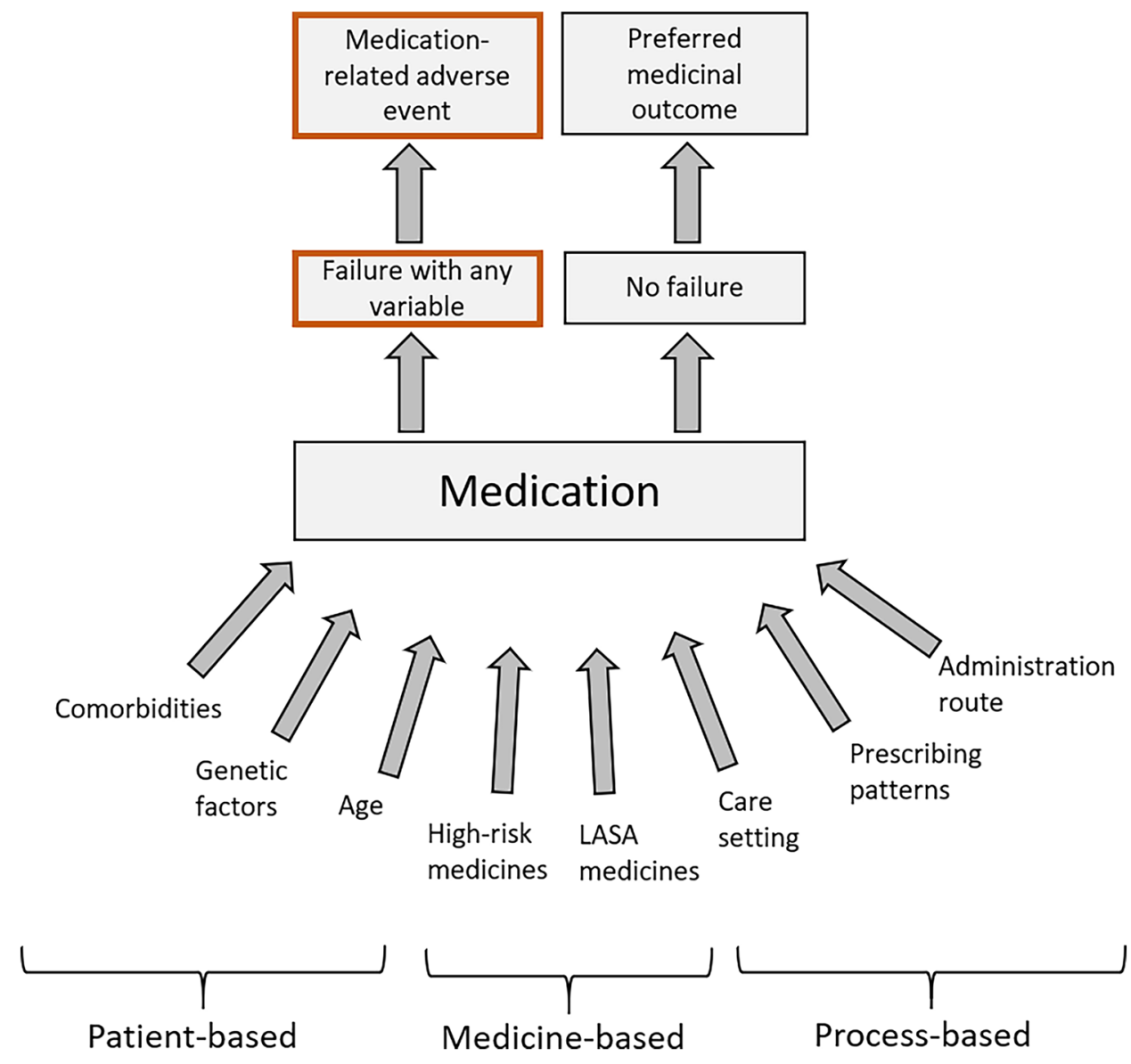

\section{Multimorbidity}

In addition to aging, changes in drug pharmacodynamics and pharmacokinetics can arise from other conditions in the general population. Multimorbidity can have a significant effect on therapeutic effect of a drug regardless of age [1, 49, 50, 54]. Similarly, polypharmacy, although most common in the aged population, will increase medication regimen complexity and predispose patients to MRAEs in all age groups. From individual conditions, decreased renal secretion and liver function have been identified as risk factors for MRAEs [2, $51,55]$. Of these conditions, decreased kidney function usually has greater clinical significance as it can rapidly alter the metabolism and disposition of drugs secreted mainly through the kidneys [46]. Although decrease in kidney function is a part of normal aging, especially quickly developing kidney diseases can have unexpected and severe consequences to pharmacological care. Hepatic dysfunction, on the other hand, will in most cases only have minor effects to drug disposition as its impact is often less straightforward. The influence can also vary even when drugs with the same metabolic pathway are taken, and the effects are also often complicated by their secondary effects on renal function [56].
Pediatric patients have been found more vulnerable to medication use due to their physiology and are more often affected by off-label use of medicines as a generally accepted practice than adults. However, pediatric patients consistently show lower numbers of medication-related hospitalizations than adults, ranging from 0.4 to $10.3 \%$ and a pooled estimate of $2.9 \%$ [57]. Similarly to adults, polypharmacy will increase the risk for MRAEs in pediatric patients as well [58].

\section{Medication-based risk factors}

The risk for MRAEs is greatly influenced by the selection of drugs used in the treatment process [59]. The risk profiles of drugs can vary considerably, and a drug is typically considered "high-risk" when it has a narrow therapeutic range of reported history of verified severe ADEs [60]. The risk can also be heightened due to specific formulations, e.g., depotpreparations, intrathecal preparations, or care situations they are used in. Accordingly, especially errors conducted with high-risk medicines can cause severe consequences to the patient [61]. Different regulatory authorities and international organizations worldwide have constituted several lists for improved recognition of high-risk medicines. 
In adult patients, such lists typically include medicine groups like anticoagulants, heparins, NSAIDs, antibacterials, diuretics, beta-blocking agents, chemotherapeutics, opioids, and psycholeptics [1, 32, 62-64]. In addition to the pharmacological and formulation-based problems, pharmaceutical preparations with higher risk for MRAEs through confusion over similar packaging or brand name or active substance name (look alike, sound-alike medicines) are also often considered in these listings $[65,66]$. Although different variations of lists have been created for different care settings, e.g., acute care and long-term care, none of them is conclusive but rather directive, as they fail to consider many special features of different units and organizations. Thus, healthcare organizations are encouraged to create and uphold their own, individual lists for more accurate recognition of unit and function-specific high-risk medicines.

\section{Process-based risk factors}

The medication process in healthcare organizations is a complex, multistage process including e.g., prescribing, transcribing, ordering, stocking, handling, preparing, dispensing, and administering medicines, demanding the joint participation of healthcare professionals from several different disciplines. Furthermore, as a patient is admitted to health care, the care process typically involves transmissions from one care setting to another, requiring fluent communication and information transfer to maintain proper medical care. In an in-hospital setting, medical care is often further complicated by the use of several invasive administration routes, that also increase the likelihood for MRAEs.

\section{Prescribing}

Previous studies show that MEs are most common during the administration and prescribing of medicines. Approximately $7 \%$ of all prescriptions are estimated to contain errors, typically resulting from inappropriate prescribing or prescribing a wrong dose [49, 66-68]. Inappropriate prescribing is, again, especially linked to the elderly, as it is estimated to affect $58 \%$ of geriatric patients and accounting for $25 \%$ of ADRs [66, 68]. Administration errors, on the other hand, are estimated to occur in $19.1 \%$ of total opportunities for errors, with approximately half of these errors occurring during the administration of intravenous drugs [69]. This is especially alarming, as administration stage errors are also estimated to be the error type least likely to be intercepted before affecting the patient, and thus, among all MEs, constitute the highest proportion of severe and fatal ADEs [70]. Other medication process stages commonly reported in MEs are transcribing errors (25.7\%), dispensing errors (18.5\%), and ordering errors (15.5\%). MEs are, however, to a lesser extent, possible in all stages of medication process $[71,72]$.

\section{Hospital admission}

When the entire hospital admission period is considered, MRAEs have been detected especially frequently immediately after admission to the hospital as well as in care interphases. For example, Bobb et al. (2004) found more than half (64\%) of MEs occurring at the time of admission [73]. This is further highlighted by latter findings, suggesting that $50 \%$ of MEs occur within 3 days of hospital admission and that major discrepancies in the majority of patients' medication regimen tend to occur at the time of admission, placing the beginning of care particularly susceptible MRAEs [72]. However, discrepancies and other MRAEs are also shown to frequently occur in patient transitions and handoffs between care sites. In care interphase, the most common errors are the omission of drug from the patient's medication regimen [74-76]. Care interphase and handoff errors have been tried to tackle with intervention by comprehensive medication reconciliation programs, with results showing a significant reduction in MRAE-related readmissions (67\%), emergency department visits (28\%), and hospital readmissions $(19 \%)$ [77, 78].

\section{MRAE surveillance in health care}

The detection and research focusing on MRAEs are a key element of medication safety: only active surveillance can provide means for prevention. Detection is also a fundamental component of pharmacovigilance and post-marketing surveillance, both of which have been proven necessary as only a small proportion of MRAEs occur during clinical trials. Although improvement leaps in this area have been made, to date MRAEs are known for being notoriously under detected and only approximately 3-10\% of MRAEs are ever identified $[40,79,80]$

Currently, the surveillance of MRAEs relies on methods that can be categorized into 3 main classes: incident reporting, direct surveillance, and computerized methods [81, 82]. All 3 methods have shown great value in both research and in clinical implications. However, differences have been observed in event detection rates and types of events between different methods [82]. Furthermore, there is major variability in the clinical usability of each method. The qualities, strengths, and limitations of each method category are presented in Table 2 .

\section{Incident reporting}

Incident reporting, mainly voluntary reporting, has been implemented for long in healthcare organizations worldwide [83]. Accordingly, it has held the status of primary detection method for MRAEs as it is both simple to execute and proven relatively cost-effective compared to e.g., direct surveillance which, although known for its thoroughness and 
Table 2 Main classes of detection methods for medication-related adverse events and most important advantages and disadvantages related to them. GTT = global trigger tool

\begin{tabular}{|c|c|c|c|}
\hline Method specifications & Incident reporting & Direct surveillance & Computerized monitoring \\
\hline Examples of used methods & $\begin{array}{l}\text { Voluntary reporting } \\
\text { Claims data }\end{array}$ & $\begin{array}{l}\text { Chart reviews } \\
\text { Patient interviews }\end{array}$ & $\begin{array}{l}\text { GTT tool } \\
\text { ICD-10 detection }\end{array}$ \\
\hline Advantages & $\begin{array}{l}\text { Reports in structured form } \\
\text { Data is easily gathered } \\
\text { Promotes culture of safety } \\
\text { Cost-effective } \\
\text { Easy to execute }\end{array}$ & $\begin{array}{l}\text { Accurate } \\
\text { Captures active errors and events } \\
\text { Wide impact } \\
\text { Good detection rates }\end{array}$ & $\begin{array}{l}\text { Multidata-source integration } \\
\text { Real-time method } \\
\text { Enables ADE prevention } \\
\text { Good detection rates } \\
\text { Efficient use of electronic } \\
\text { data on entire organization } \\
\text { level }\end{array}$ \\
\hline Limitations & $\begin{array}{l}\text { Underreporting } \\
\text { only allows retrospective analyses } \\
\text { Variable quality of reports } \\
\text { Blame culture }\end{array}$ & $\begin{array}{l}\text { Costly } \\
\text { Time-consuming } \\
\text { Requires trained personnel for every } \\
\text { unit where executed }\end{array}$ & $\begin{array}{l}\text { Inserted errors } \\
\text { Poor triggers } \\
\text { Alert fatigue } \\
\text { Requires expert assessment } \\
\text { for actions to triggers }\end{array}$ \\
\hline
\end{tabular}

good sensitivity, is laborious and expensive [84]. However, compared to the other two methods, incident reporting is undermined by significant underreporting, even when it is encouraged within healthcare personnel [85]. Furthermore, voluntary reporting has been found to mainly pick out latent errors with potentially harmful outcomes and events causing only minor harm thus leaving more serious types of MRAEs undetected $[80,83,86]$. Using voluntary reporting alone, it is not possible to form reliable estimates of the overall number of MRAEs.

\section{Direct surveillance and computerized methods}

Compared to incident reporting, both direct surveillance and computerized methods can form better estimates of the overall prevalence of MRAEs, as both methods have shown better detection rates up to eightfold to that of voluntary reporting $[81,82,84,85]$. Furthermore, as direct surveillance is usually conducted as real-time chart reviews or patient interviews and computerize methods as global trigger tool-type real-time alert-system, they both provide a clear advantage to incident reporting, which can only provide information for retrospective analyses. This enables faster responses to intervein and prevent serious harm related to MRAEs within healthcare units but also faster reactions to necessary changes on an organizational level. In direct surveillance, trained professionals are needed to be placed in every unit where surveillance is wanted, whereas one well-established trigger tool system can cover data from the entire organization. Nevertheless, it should be noted that trigger tools are only as good as the triggers they work by and that expert assessment of each alert is still required for selecting the appropriate actions for managing the situation [87]. Furthermore, direct surveillance remains the only reliable method for real-time detection of administration errors in the units and, without voluntary reporting, valuable information on inadequate processes and protocols resulting in MRAEs is inevitably lost. Thus, for the best possible coverage of MRAEs, variable combinations of each method category should be applied.

\section{Discussion}

It is well established that MRAEs are a prevalent problem in health care, forming as severe of a health hazard in the western countries as malaria and tuberculosis do in the developing countries. Although MRAEs cause significant functional and economical challenges already, the impact of these events is estimated to further increase along with aging population and growing numbers of medication use all over the world. More than ever, research and patient safety work has focused on endeavors in active prevention of medication-related patient harm. It has given means to fight unwanted events by identifying risk factors related to medicines, processes, and patients in the medication process. However, we have also learned that simple solutions for eliminating the problem altogether are not available as the field is continuously changing and evolving. Thus, it is only through continuous research and method development that we can tackle and prevent medication-related problems as they arise.

All research is based on event detection and recognition. During the last decade, computerized methods have opened possibilities to answer to the growing demand of continuously increasing amount of electronic data in health care, combining different types of data sources, and automatizing information categorization. When combined with machine learning, computerized methods could provide further possibilities in event forecasting in all MRAE subtypes [88, 89]. This requires multidisciplinary strives from pharmacological, medical, and information technologies and could change 
the currently prevailing trend of preventative work through retrospective observations, also altering the nature of preventative work from trial and error to real-time actions and on-point prevention of patient harm. Such systems could also provide valuable information from other fields of medicine benefitting multiple functions within healthcare organizations, e.g., knowledge-based decision making and rational treatment $[90,91]$. In the future, pharmacovigilance research and patient safety efforts should prioritize the supporting of collaborative research between computer science and medicine to create opportunities for the development of intelligent methods for preventative work.

There are several limitations to this article. As narrative review, this study does not provide a systematic and conclusive literature search of the topic. Therefore, it is possible that some factors related to the topics within this review are not reported here. Accordingly, this review does not provide any exhaustive quantification of medication safety issues presented here. However, in this article, it is possible to discuss the issues related to medical care without focusing on specific problem or variable and thus provides a comprehensive overview of the current status of medication-related problems in health care.

Author contribution All authors contributed significantly to the writing of the review. OL conducted the literature search. OL, SS, and ML drafted the outlines of extractable data from the selected articles, and the topics addressed in this narrative review. OL wrote the manuscript draft. SS and ML commented and edited the draft.

Funding Open access funding provided by University of Oulu including Oulu University Hospital.

\section{Declarations}

Conflict of interest The authors declare no competing interests.

Open Access This article is licensed under a Creative Commons Attribution 4.0 International License, which permits use, sharing, adaptation, distribution and reproduction in any medium or format, as long as you give appropriate credit to the original author(s) and the source, provide a link to the Creative Commons licence, and indicate if changes were made. The images or other third party material in this article are included in the article's Creative Commons licence, unless indicated otherwise in a credit line to the material. If material is not included in the article's Creative Commons licence and your intended use is not permitted by statutory regulation or exceeds the permitted use, you will need to obtain permission directly from the copyright holder. To view a copy of this licence, visit http://creativecommons.org/licenses/by/4.0/.

\section{References}

1. Alhawassi TM, Krass I, Bajorek BV, Pont LG (2014) A systematic review of the prevalence and risk factors for adverse drug reactions in the elderly in the acute care setting. Clin Interv Aging 9:2079-2086. https://doi.org/10.2147/CIA.S71178

2. Krähenbühl-Melcher A, Schlienger R, Lampert M et al (2007) Drug-related problems in hospitals. Drug Saf 30:379-407. https:// doi.org/10.2165/00002018-200730050-00003

3. Panagioti M, Khan K, Keers RN et al (2019) Prevalence, severity, and nature of preventable patient harm across medical care settings: systematic review and meta-analysis. BMJ (Clinical research ed) 366:14185. https://doi.org/10.1136/bmj.14185

4. Walsh EK, Hansen CR, Sahm LJ et al (2017) Economic impact of medication error: a systematic review. Pharmacoepidemiol Drug Saf 26:481-497. https://doi.org/10.1002/pds.4188

5. World Health Organization (2002) Safety of medicines - a guide to detecting and reporting adverse drug reactions - why health professionals need to take action

6. Becker SC Questions about NCC MERP and medication errors. https://doi.org/10.1136/qshc.2004.010611

7. Ferner RE, Aronson JK (2006) Clarification of terminology in medication errors definitions and classification

8. Choi I, Lee SM, Flynn L et al (2016) Incidence and treatment costs attributable to medication errors in hospitalized patients. Res Social Adm Pharm 12:428-437. https://doi.org/10.1016/j. sapharm.2015.08.006

9. Härkänen $M$, Turunen H, Saano S, Vehviläinen-Julkunen K (2015) Detecting medication errors: analysis based on a hospital's incident reports. Int J Nurs Pract 21:141-146. https://doi. org/10.1111/ijn.12227

10. Kunac DL, Kennedy J, Austin N, Reith D (2009) Incidence, preventability, and impact of adverse drug events (ADEs) and potential ADEs in hospitalized children in New Zealand. Pediatr Drugs 11:153-160. https://doi.org/10.2165/00148581200911020-00005

11. Dequito AB, Mol PGM, van Doormaal JE et al (2011) Preventable and non-preventable adverse drug events in hospitalized patients. Drug Saf 34:1089-1100. https://doi.org/10.2165/ 11592030-000000000-00000

12. Davies EC, Green CF, Taylor S et al (2009) Adverse drug reactions in hospital in-patients: a prospective analysis of 3695 patient-episodes. PLoS One 4 https://doi.org/10.1371/journal. pone.0004439

13. Clementi E, Perrone V, Conti V et al (2014) Seriousness, preventability, and burden impact of reported adverse drug reactions in Lombardy emergency departments: a retrospective 2-year characterization. ClinicoEcon Outcomes Res 6:505. https://doi.org/10. 2147/CEOR.S71301

14. de Vries EN, Ramrattan MA, Smorenburg SM et al (2008) The incidence and nature of in-hospital adverse events: a systematic review. Qual Saf Health Care 17:216-223. https://doi.org/10. 1136/qshc.2007.023622

15. Bouvy JC, de Bruin ML, Koopmanschap MA (2015) Epidemiology of adverse drug reactions in Europe: a review of recent observational studies. Drug Saf 38:437-453. https://doi.org/10. 1007/s40264-015-0281-0

16. Hakkarainen KM, Hedna K, Petzold M, Hägg S (2012) Percentage of patients with preventable adverse drug reactions and preventability of adverse drug reactions - a meta-analysis. PLoS One 7:e33236. https://doi.org/10.1371/journal.pone.0033236

17. Miguel A, Azevedo LF, Araújo M, Pereira AC (2012) Frequency of adverse drug reactions in hospitalized patients: a systematic review and meta-analysis. Pharmacoepidemiol Drug Saf 21:1139 1154. https://doi.org/10.1002/pds.3309

18. Keers RN, Williams SD, Cooke J et al (2014) Impact of interventions designed to reduce medication administration errors in hospitals: a systematic review. Drug Saf 37:317-332. https://doi. org/10.1007/s40264-014-0152-0 
19. Bouvy JC, de Bruin ML, Koopmanschap MA (2015) Epidemiology of adverse drug reactions in Europe: a review of recent observational studies. Drug Saf. https://doi.org/10.1007/ s40264-015-0281-0

20. Juntti-Patinen L, Kuitunen T, Pere P, Neuvonen PJ (2006) Drugrelated visits to a district hospital emergency room. Basic Clin Pharmacol Toxicol 98:212-217

21. Pedrós C, Quintana B, Rebolledo M et al (2014) Prevalence, risk factors and main features of adverse drug reactions leading to hospital admission. Eur J Clin Pharmacol 70:361-367. https:// doi.org/10.1007/s00228-013-1630-5

22. el Morabet N, Uitvlugt EB, van den Bemt BJ et al (2018) Prevalence and preventability of drug-related hospital readmissions: a systematic review. J Am Geriatr Soc 66:602-608. https://doi. org/10.1111/jgs.15244

23. Viana L de G, Martins MAP, Passaglia LG, et al (2018) Evaluation of accuracy of IHI Trigger Tool in identifying adverse drug events: a prospective observational study. Br. J. Clin Pharmacol 84:2252-2259. https://doi.org/10.1111/bcp.13665

24. de Boer M, Boeker EB, Ramrattan MA, et al (2013) Adverse drug events in surgical patients: An observational multicentre study. Int J Clin Pharm 35:744-752. https://doi.org/10.1007/ s11096-013-9797-5

25. Giardina C, Cutroneo PM, Mocciaro E, et al (2018) Adverse drug reactions in hospitalized patients: Results of the FORWARD (facilitation of reporting in hospital ward) study. Front Pharmacol 9. https://doi.org/10.3389/fphar.2018.00350

26. Smith KM, Jeske CS, Young B, Hatton J (2006) Prevalence and characteristics of adverse drug reactions in neurosurgical intensive care patients. Neurosurgery 58:426-431.https://doi. org/10.1227/01.NEU.0000197321.57853.83

27. Kaushal R, Bates DW, Landrigan C, et al (2001) Medication errors and adverse drug events in pediatric inpatients. JAMA 285:2114-20

28. Thompson $\mathrm{R}$, Whennan L, Liang J, et al (2015) Investigating the Frequency and Nature of Medication-Related Problems in the Women's Health Unit of an Australian Tertiary Teaching Hospital. Annals of Pharmacotherapy 49:770-776. https://doi. org/10.1177/1060028015581009

29. Urbina O, Ferrández O, Luque S, et al (2014) Patient risk factors for developing a drug-related problem in a cardiology ward. Therapeutics and Clinical Risk Management 11:9-15. https:// doi.org/10.2147/TCRM.S71749

30. Edwards R, Aronson J (2000) Adverse drug reactions: definitions, diagnosis, and management. The Lancet 356:1255-1259. https://doi.org/10.1016/S0140-6736(00)02799-9

31. Oscanoa TJ, Lizaraso F, Carvajal A (2017) Hospital admissions due to adverse drug reactions in the elderly. A meta-analysis. Eur J Clin Pharmacol 73:759-770. https://doi.org/10.1007/ s00228-017-2225-3

32. Wolfe D, Yazdi F, Kanji S et al (2018) Incidence, causes, and consequences of preventable adverse drug reactions occurring in inpatients: a systematic review of systematic reviews

33. Kiekkas P, Karga M, Lemonidou C et al (2011) Medication errors in critically ill adults: a review of direct observation evidence. American journal of critical care : an official publication, American Association of Critical-Care Nurses 20:36-44. https://doi.org/10.4037/ajcc2011331

34. Alshehri GH, Keers RN, Ashcroft DM (2017) Frequency and nature of medication errors and adverse drug events in mental health hospitals: a systematic review. Drug Saf 40:871-886. https://doi.org/10.1007/s40264-017-0557-7

35. European Commission (2008) Proposal for a regulation amending, as regards pharmacovigilance of medicinal products for human use. Regulation (EC) No 726/2004. Impact assessment. I:12. https://doi.org/10.1017/S001447970700590X
36. Ernst FR, Grizzle AJ (1996) Drug-related morbidity and mortality: updating the cost-of-illness model. J Am Pharm Assoc Washington, DC 41:192-9

37. Bates DW, Spell N, Cullen DJ et al (1997) The costs of adverse drug events in hospitalized patients. Adverse Drug Events Prevention Study Group. JAMA 277:307-11

38. Johnson J, Bootman J (1995) Drug-related morbidity and mortality. A cost-of-illness model. - PubMed - NCBI. Arch Intern Med 155:1949-1956

39. Hoonhout L, MC de BCW et al (2010) Nature, occurrence and consequences of medication-related adverse events during hospitalization. Drug Saf 33:853-864. https://doi.org/10.2165/ 11536800-000000000-00000

40. Classen DC, Pestotnik SL, Evans RS et al (1997) Adverse drug events in hospitalized patients. Excess length of stay, extra costs, and attributable mortality. JAMA 277:301. https://doi. org/10.1001/jama.1997.03540280039031

41. Marques FB, Penedones A, Mendes D, Alves C (2016) A systematic review of observational studies evaluating costs of adverse drug reactions. ClinicoEconomics and Outcomes Research 8:413-426. https://doi.org/10.2147/CEOR.S115689

42. de Almeida SM, Romualdo A, de Abreu FA et al (2017) Use of a trigger tool to detect adverse drug reactions in an emergency department. BMC Pharmacol Toxicol 18:71. https://doi.org/10. 1186/s40360-017-0177-y

43. Cullen DJ, Sweitzer BJ, Bates DW et al (1997) Preventable adverse drug events in hospitalized patients. Crit Care Med 25:1289-1297. https://doi.org/10.1097/00003246-199708000-00014

44. Zhan C, Miller MR (2003) Excess length of stay, charges, and mortality attributable to medical injuries during hospitalization. JAMA 290:1868. https://doi.org/10.1001/jama.290.14.1868

45. Wu WK, Pantaleo N (2003) Evaluation of outpatient adverse drug reactions leading to hospitalization. Am J Health Syst Pharm 60:253-259. https://doi.org/10.1093/ajhp/60.3.253

46. Canet MJ, Cherrington NJ (2014) Drug disposition alterations in liver disease: extrahepatic effects in cholestasis and nonalcoholic steatohepatitis. Expert Opin Drug Metab Toxicol 10:1209-1219. https://doi.org/10.1517/17425255.2014.936378

47. Notenboom K, Beers E, van Riet-Nales DA et al (2014) Practical problems with medication use that older people experience: a qualitative study. J Am Geriatr Soc 62:2339-2344. https://doi. org/10.1111/jgs.13126

48. Sim SC, Kacevska M, Ingelman-Sundberg M (2013) Pharmacogenomics of drug-metabolizing enzymes: a recent update on clinical implications and endogenous effects. Pharmacogenomics J 13:1-11. https://doi.org/10.1038/tpj.2012.45

49. Asaad Assiri G, Atef Shebl N, Adam Mahmoud M et al (2018) What is the epidemiology of medication errors, error-related adverse events and risk factors for errors in adults managed in community care contexts? A systematic review of the international literature. BMJ Open 8:19101. https://doi.org/10.1136/ bmjopen-2017-019101

50. Härkänen M, Vehviläinen-Julkunen K, Murrells T et al (2018) Medication administration errors and mortality: Incidents reported in England and Wales between 2007-2016. Res Social Adm Pharm. https://doi.org/10.1016/J.SAPHARM.2018.11.010

51. Sánchez Muñoz-Torrero JF, Barquilla P, Velasco R et al (2010) Adverse drug reactions in internal medicine units and associated risk factors. Eur J Clin Pharmacol 66:1257-1264. https://doi.org/ 10.1007/s00228-010-0866-6

52. Beijer HJM, de Blaey CJ (2002) Hospitalisations caused by adverse drug reactions (ADR): a meta-analysis of observational studies. Pharm World Sci : PWS 24:46-54

53. Bénard-Laribière $\mathrm{A}$, Miremont-Salamé G, Pérault-Pochat M-C et al (2015) Incidence of hospital admissions due to adverse drug 
reactions in France: the EMIR study. Fundam Clin Pharmacol 29:106-111. https://doi.org/10.1111/fcp.12088

54. Mangoni AA, Jackson SHD (2004) Age-related changes in pharmacokinetics and pharmacodynamics: basic principles and practical applications. Br J Clin Pharmacol 57:6-14. https://doi.org/10. 1046/j.1365-2125.2003.02007.x

55. Takahashi Y, Sakuma M, Murayama H, Morimoto T (2018) Effect of baseline renal and hepatic function on the incidence of adverse drug events: the Japan adverse drug events study. Drug Metab Pers Ther 33:165-173. https://doi.org/10.1515/dmpt-2018-0018

56. Tan Y, Hu Y, Liu X et al (2016) Improving drug safety: from adverse drug reaction knowledge discovery to clinical implementation. Methods 110:14-25. https://doi.org/10.1016/J.YMETH. 2016.07.023

57. Smyth RMD, Gargon E, Kirkham J et al (2012) Adverse drug reactions in children-a systematic review. PLoS One 7:e24061. https://doi.org/10.1371/journal.pone.0024061

58. Lombardi N, Crescioli G, Bettiol A et al (2019) Characterization of serious adverse drug reactions as cause of emergency department visit in children: a 5-years active pharmacovigilance study. https://doi. org/10.1186/s40360-018-0207-4

59. Zegers M, de Bruijne MC, Wagner C et al (2009) Adverse events and potentially preventable deaths in Dutch hospitals: results of a retrospective patient record review study. Qual Saf Health Care 18:297-302. https://doi.org/10.1136/qshc.2007.025924

60. Sheikh A, Dhingra-Kumar N, Kelley E et al (2017) The third global patient safety challenge: tackling medication-related harm. Bulletin of the World Health Organization

61. Hohl CM, Zed PJ, Brubacher JR et al (2010) Do emergency physicians attribute drug-related emergency department visits to medication-related problems? Ann Emerg Med 55:493-502.e4. https://doi.org/10.1016/j.annemergmed.2009.10.008

62. Institute for Safe Medication Practices (2011) ISMP List of highalert medications in community/ambulatory healthcare. 2016

63. Hohl CM, Dankoff J, Colacone A, Afilalo M (2001) Polypharmacy, adverse drug-related events, and potential adverse drug interactions in elderly patients presenting to an emergency department. Ann Emerg Med 38:666-671. https://doi.org/10.1067/ MEM.2001.119456

64. Lapatto-Reiniluoto O, Patinen L, Niemi M et al (2015) Drugrelated inadvertent deaths in a university hospital - a declining trend. Basic Clin Pharmacol Toxicol 117:421-426. https://doi.org/ 10.1111/bcpt.12435

65. Emmerton LM, Rizk MFS (2012) Look-alike and sound-alike medicines: risks and 'solutions.' Int J Clin Pharm 34:4-8. https:// doi.org/10.1007/s11096-011-9595-x

66. Barry PJ, Gallagher P, Ryan C, O'mahony D (2007) START (screening tool to alert doctors to the right treatment) an evidencebased screening tool to detect prescribing omissions in elderly patients. Age Ageing 36:632-638. https://doi.org/10.1093/ageing/ afm118

67. Lewis PJ, Dornan T, Taylor D et al (2009) Prevalence, incidence and nature of prescribing errors in hospital inpatients. Drug Saf 32:379-389. https://doi.org/10.2165/00002018-200932050-00002

68. Passarelli MCG, Jacob-Filho W, Figueras A (2005) Adverse drug reactions in an elderly hospitalised population. Drugs Aging 22:767-777. https://doi.org/10.2165/00002512-200522090-00005

69. McLeod MC, Barber N, Franklin BD (2013) Methodological variations and their effects on reported medication administration error rates. BMJ Qual Saf 22:278-289. https://doi.org/10. 1136/BMJQS-2012-001330

70. Cousins D, Gerrett D, Richards N, Jadeja MM (2015) Initiatives to identify and mitigate medication errors in England. Drug Saf 38:349-357. https://doi.org/10.1007/s40264-015-0270-3

71. Beso A, Franklin BD, Barber N (2005) The frequency and potential causes of dispensing errors in a hospital pharmacy. Pharm World Sci 27:182-190. https://doi.org/10.1007/ s11096-004-2270-8

72. Ben-Yehuda A, Bitton Y, Sharon P et al (2011) Risk factors for prescribing and transcribing medication errors among elderly patients during acute hospitalization. Drugs Aging 28:491-500. https://doi.org/10.2165/11590610-000000000-00000

73. Bobb A, Gleason K, Husch M et al (2004) The epidemiology of prescribing errors: the potential impact of computerized prescriber order entry. Arch Intern Med 164:785-792. https://doi.org/ 10.1001/archinte.164.7.785

74. Belda-Rustarazo S, Cantero-Hinojosa J, Salmeron-García A et al (2015) Medication reconciliation at admission and discharge: an analysis of prevalence and associated risk factors. Int J Clin Pract 69:1268-1274. https://doi.org/10.1111/ijcp.12701

75. Boockvar KS, Livote EE, Goldstein N et al (2010) Electronic health records and adverse drug events after patient transfer. Qual Saf Health Care 19:e16. https://doi.org/10.1136/qshc.2009. 033050

76. Breuker C, Macioce V, Mura T et al (2017) Medication errors at hospital admission and discharge. J Patient Saf 1. https://doi.org/ 10.1097/PTS.0000000000000420

77. Cornish PL, Knowles SR, Marchesano R et al (2005) Unintended medication discrepancies at the time of hospital admission. Arch Intern Med 165:424. https://doi.org/10.1001/archinte.165.4.424

78. van Doormaal JE, van den Bemt PMLA, Mol PGM et al (2009) Medication errors: the impact of prescribing and transcribing errors on preventable harm in hospitalised patients. Qual Saf Health Care 18:22-27. https://doi.org/10.1136/qshc.2007.023812

79. Naessens JM, Campbell CR, Huddleston JM et al (2009) A comparison of hospital adverse events identified by three widely used detection methods. Int J Qual Health Care 21:301-307. https:// doi.org/10.1093/intqhe/mzp027

80. Tchijevitch OA, Nielsen LP, Lisby M (2017) Life-threatening and fatal adverse drug events in a Danish University Hospital. J Patient Saf 1. https://doi.org/10.1097/PTS.0000000000000411

81. Manias E (2013) Detection of medication-related problems in hospital practice: a review. Br J Clin Pharmacol 76:7-20. https:// doi.org/10.1111/bcp.12049

82. Thürmann P (2001) Methods and systems to detect adverse drug reactions in hospitals. Drug Saf 24:961-968. https://doi.org/10. 2165/00002018-200124130-00003

83. Milch CE, Salem DN, Pauker SG et al (2006) Voluntary electronic reporting of medical errors and adverse events: an analysis of 92,547 reports from 26 acute care hospitals. J Gen Intern Med 21:165-170. https://doi.org/10.1111/j.1525-1497.2006.00322.x

84. Gandhi T, Seder D, Bates D (2000) Methodology matters. Identifying drug safety issues: from research to practice. Int J Qual Health Care 12:69-76. https://doi.org/10.1093/intqhe/12.1.69

85. Montesi G, Lechi A (2009) Prevention of medication errors: detection and audit. Br J Clin Pharmacol 67:651-655. https://doi. org/10.1111/j.1365-2125.2009.03422.x

86. Nuckols TK, Bell DS, Liu H et al (2007) Rates and types of events reported to established incident reporting systems in two US hospitals. Qual Saf Health Care 16:164-168. https://doi.org/10.1136/ qshc.2006.019901

87. Molokhia M, Tanna S, Bell D (2009) Improving reporting of adverse drug reactions: Systematic review. Clin Epidemiol $1: 75-92$

88. Torkamani A, Andersen KG, Steinhubl SR, Topol EJ (2017) Highdefinition medicine. Cell 170:828-843

89. Bi Q, Goodman KE, Kaminsky J, Lessler J (2019) What is machine learning? A primer for the epidemiologist. Am J Epidemiol 188:2222-2239. https://doi.org/10.1093/aje/kwz189

90. Dwyer DB, Falkai P, Koutsouleris N (2018) Machine learning approaches for clinical psychology and psychiatry. Annu Rev Clin Psychol 14:91-118 
91. Shameer K, Johnson KW, Glicksberg BS et al (2018) Machine learning in cardiovascular medicine: are we there yet? Heart 104:1156-1164
Publisher's Note Springer Nature remains neutral with regard to jurisdictional claims in published maps and institutional affiliations. 